\title{
Psychological interventions in the management of common skin conditions
}

This article was published in the following Dove Press journal:

Psychology Research and Behavior Management

25 March 2010

Number of times this article has been viewed

\author{
Philip D Shenefelt \\ Department of Dermatology and \\ Cutaneous Surgery, College \\ of Medicine, University \\ of South Florida, Tampa, Florida, USA
}

Correspondence: Philip D Shenefelt

Department of Dermatology and Cutaneous Surgery, MDC 079, College of Medicine, University of South Florida, I290I Bruce B Downs Blvd, Tampa,

Florida 33612 , USA

Tel + I 8139742188

Fax + I 8139744272

Email pshenefe@health.usf.edu

\begin{abstract}
The nervous system and the skin develop next to each other in the embryo and remain intimately interconnected and interactive throughout life. The nervous system can influence skin conditions through psychoneuroimmunoendocrine mechanisms and through behaviors. Understanding the pathophysiology aids in selection of treatment plans for correcting the negative effects of the psyche on specific skin conditions. Medication options include standard psychotropic medications and alternative herbs and supplements. Other options include biofeedback, cognitive-behavioral methods, hypnosis, meditation, progressive relaxation, the placebo effect, and suggestion. When simple measures fail, combining medications with other therapeutic options may produce better results. Skin conditions that have strong psychophysiologic aspects may respond well to techniques such as biofeedback, cognitive-behavioral methods, hypnosis, meditation, or progressive relaxation that help to counteract stress. Treatment of primary psychiatric disorders that negatively influence skin conditions often results in improvement of those skin conditions. Abnormal conditions of the skin, hair, and nails can also influence the psyche negatively. Treatment of secondary psychiatric disorders such as anxiety or depression that are triggered or exacerbated by the appearance of these skin conditions or the associated discomfort may also be required.
\end{abstract}

Keywords: psychodermatology, psychosomatic, psychocutaneous, skin disorders, treatment, standard, alternative, non-drug

\section{Overview of psychocutaneous disorders}

The nervous system and the skin begin to form and develop side by side in the top layer or ectoderm of the fetus and remain intimately interconnected and interactive throughout life. The neural receptors in the skin may be viewed as the largest sense organ of the body and are key to skin protection and health. Many skin disorders have a significant psychosomatic or behavioral element. ${ }^{1}$ Nervous system-skin interactions allow drug and non-drug psychotherapeutic interventions that produce positive effects on many cutaneous diseases. These effects occur through actions of drugs, the autonomic nervous system, local hormones, and neuropeptides, resulting in neurogenic modulation of cutaneous inflammation. ${ }^{2}$ The skin is also affected by brain-regulated behavioral habits which alter exposure to various environmental factors such as sun exposure, and occupational and recreational exposures to animals, plants, and chemicals, and climate changes associated with travel. Skin disorders often have negative effects on the patient's psychological and social status. Drug and non-drug interventions may help ameliorate the negative effects of the skin disorder on the psyche. ${ }^{3}$ A combined approach using both drug and non-drug methods is often needed when treating complex cutaneous

submit your manuscript $\mid$ www.dovepress.com 
psychosomatic and somatopsychosocial problems. Patients who are referred by a dermatologist or family physician to a psychiatrist or psychologist often refuse the referral or fail to keep the appointment. Few dermatologists are adequately cross-trained in psychiatry or psychology. A recent review of psychodermatology covered the relevant literature from 1951 to $2004 .^{4}$ The development of subspecialty training in psychodermatology is currently being considered. ${ }^{5}$ How important the psychosocial aspects of skin, hair, and nails are to many individuals is reflected in the large amount of money spent on skin, hair, and nail products, and on cosmetic skin procedures.

\section{Skin disorders with psychophysiologic aspects \\ Stress and emotion}

Inflammatory and sensory skin disorders are significantly influenced by stress and emotion. Griesemer, who trained both as a dermatologist and as a psychiatrist, estimated the effect that emotions had on skin disease for each patient he saw during one year in his practice. From these data he developed an index ${ }^{6}$ of the effects of emotions on specific skin disorders. ${ }^{7}$ The pathways by which stress and emotion affect the nervous system, immune system, and hormonal system and their subsequent effects on inflammation and autonomic functioning and on the skin are still being elucidated. ${ }^{8}$ Stress can induce or exacerbate anxiety disorders or depression in susceptible individuals. Drugs that reduce anxiety or depression can be helpful in those individuals. No direct anti-stress drug had yet been developed. The nondrug modalities of relaxation, biofeedback, meditation, or self-hypnosis can counteract stress and emotion. ${ }^{9}$ Simple inexpensive temperature-sensitive stress cards can be used to promote hand warming, which is associated with relaxation. ${ }^{10}$ Heart rate variability (HRV) biofeedback accompanied by slower deeper breathing can also reduce the effects of stress and emotion. ${ }^{11}$ Compact, highly portable, handheld HRV biofeedback devices such as the HeartMath emWave ${ }^{\circledR}$ personal stress reliever and the StressEraser ${ }^{\circledR}$ have recently become available.

\section{Stress and emotion reduction in skin conditions}

Inflammatory, immune-mediated, and behavioral skin disorders are influenced by psychosomatic factors. ${ }^{12}$ In a recent study, $10 \%$ of patients at a dermatology clinic had psychosomatic disorders and another $15 \%$ had adjustment disorders. ${ }^{13}$ In conjunction with other appropriate treatments for the skin disorders, reducing stress, emotions, and behavioral habits that impair healing or damage to skin, hair, or nails can enhance response to treatment. Associated anxiety or depression can be treated with anxiolytic drugs or antidepressants. ${ }^{14}$ Non-drug methods of stress reduction such as relaxation, meditation, self-hypnosis, physical exercise, or biofeedback can directly counteract the stress.

\section{Acne}

Acne vulgaris often flares with stress and premenstrually. ${ }^{15}$ With worsening of the acne, many individuals get more stressed, setting up a vicious cycle. Conventional acne treatments can help control the acne, reducing the patient's stress about having the acne. Stress may also be lessened with relaxation training ${ }^{16}$ or another of the above-mentioned methods.

\section{Alopecia areata}

Alopecia areata usually occurs as patchy bald spots where immune dysregulation results in the hair follicles being attacked by inflammatory T-lymphocytes. Alexithymia with difficulty recognizing and describing feelings and dissociative somatization has been reported to be more common in adults with alopecia areata than in controls. ${ }^{17}$ Stress can initiate or worsen alopecia areata. ${ }^{18}$ The hair loss can aggravate the stress, especially if the hair loss is visible to others. Self-image issues and stress may be treated with self-hypnosis ${ }^{19}$ or another of the aforementioned methods.

\section{Atopic dermatitis}

Atopic dermatitis is produced mainly by scratching and flares with stress though psychoneuroimmunomechanisms. ${ }^{20}$ Worsening atopic dermatitis can further stress the patient, who then tends to scratch more and further worsen the dermatitis. Stress may be lessened with cognitivebehavioral methods, ${ }^{21}$ hypnosis or self-hypnosis, ${ }^{22}$ or another of the above-mentioned methods. If indicated, adjunctive anxiolytic drugs or antidepressants may be employed.

\section{Dermatitis artifacta}

Self-induced factitial damage to the skin often occurs in odd otherwise unexplainable forms and may indicate a seriously disturbed patient or may occur for secondary gain. ${ }^{23}$ Consultation with a psychiatrist or psychologist is recommended. Often the patient denies self-inflicting the trauma 
and frequently is noncompliant in obtaining a psychiatric evaluation.

\section{Dyshidrosis}

Dyshidrosis consisting of tiny blisters on palms and/or soles typically flares with stress. ${ }^{6}$ In addition to conventional topical treatments, stress reduction can be of benefit. Stress may be reduced by HRV biofeedback, or galvanic skin response (GSR) biofeedback ${ }^{24}$ or another of the above-mentioned methods.

\section{Erythema nodosum}

Erythema nodosum with deep painful red nodules on the legs may worsen with stress. The author has reported a case of resolution of intractable erythema nodosum following hypnoanalysis. ${ }^{25}$

\section{Herpes simplex}

Stress frequently initiates or exacerbates herpes simplex cold sore virus recurrences. ${ }^{26}$ Along with using conventional antiviral treatments for the herpes, stress reduction may be facilitated with self-hypnosis ${ }^{27}$ or another of the aforementioned methods.

\section{Hyperhidrosis}

Hyperhidrosis of hands, feet, axillae, or forehead has a clear rapid onset correlation with stress. ${ }^{6}$ Locally injected botulinum toxin $\left(\right.$ Botox $^{\circledR}$ ) can temporarily inactivate acetylcholine release from the nerves associated with sweating. ${ }^{28}$ Stress may be reduced with GSR biofeedback, or HRV biofeedback ${ }^{29}$ or another of the above-mentioned methods.

\section{Lichen planus}

Lichen planus, an inflammatory pruritic dermatosis, is often triggered or exacerbated by stress. The intense itching and discoloration with hyperpigmentation that typically occur with lichen planus can further fuel the stress. As an indicator of stress, elevated salivary cortisol levels have been detected in patients with oral lichen planus. ${ }^{30}$ The stress may be reduced using self-hypnosis ${ }^{27}$ or another of the aforementioned methods.

\section{Lichen simplex chronicus}

Thickened plaques of lichen simplex chronicus are produced by rubbing or scratching the skin and are initiated or exacerbated by stress. In some cases, dissociation with somatization may play a role. ${ }^{31}$ Along with standard topical treatments, stress reduction can be beneficial. The stress may be reduced with self-hypnosis ${ }^{27}$ or another of the above-mentioned methods.

\section{Neurotic excoriations}

Neurotic excoriations are skin damage self-induced by scratching, ${ }^{32}$ and neurotic or psychogenic excoriations are worsened by stress. The stress may be lessened with selfhypnosis $^{33}$ or another of the aforementioned methods. The commonly associated anxiety or depression may be treated with adjunctive anxiolytic drugs or antidepressants.

\section{Nummular dermatitis}

Nummular dermatitis consists of coin-shaped patches on dry areas of skin and in some individuals can flare with stress. Connections of nerves to mast cells have been noted in the basement membrane zone in nummular dermatitis. ${ }^{34}$ Along with standard topical treatments, stress reduction can be helpful. The stress may be reduced using self-hypnosis ${ }^{27}$ or another of the above-mentioned methods.

\section{Perioral dermatitis}

Perioral dermatitis, similar to acne but located around the mouth, can be exacerbated by stress or other neurogenic factors. ${ }^{35}$ Along with conventional topical treatments, stress reduction can be useful. The stress may be reduced with selfhypnosis ${ }^{27}$ or another of the aforementioned methods.

\section{Pruritus}

Pruritus or itching is frequently worsened by stress. Many inflammatory skin diseases are itchy via neuroimmunoendocrine mechanisms. ${ }^{36}$ See later under neurogenic cutaneous sensory dysesthesias for further discussion of pruritus and its treatment. Stress reduction can be helpful. The stress may be lessened with self-hypnosis ${ }^{27}$ or another of the abovementioned methods.

\section{Psoriasis}

Psoriasis in many patients flares with stress. ${ }^{37}$ Along with standard treatments, stress reduction can help reduce flares. Many patients are distressed by the disfigurement of the skin by the psoriatic lesions. Alexithymia with dissociative somatization can aggravate psoriasis and has a higher risk of associated alcoholism. ${ }^{38}$ Body image issues and stress and may be improved with cognitive-behavioral methods, ${ }^{39}$ biofeedback, meditation, ${ }^{40}$ relaxation training, or self-hypnosis. ${ }^{41}$

\section{Rosacea}

With rosacea the facial flushing and the papular inflammations both can flare with stress. ${ }^{42}$ Many rosacea patients are 
in turn distressed by their facial appearance. Stress may be reduced with self-hypnosis ${ }^{27}$ or another of the abovementioned methods.

\section{Seborrheic dermatitis}

Stress frequently worsens the scaling and itching of seborrheic dermatitis. ${ }^{36}$ In addition to conventional treatments for the seborrheic dermatitis, stress may be reduced using selfhypnosis ${ }^{27}$ or another of the aforementioned methods.

\section{Telogen effluvium}

Telogen effluvium is diffuse hair loss and may be acute or chronic. Common initiators are stress, low protein intake, and hormonal changes. ${ }^{43}$ Stress may be reduced with one of the above mentioned methods. Any accompanying depression may be treated with an antidepressant. ${ }^{14}$

\section{Trichotillomania}

Stress can worsen the repetitive pulling and twisting behavior that produces trichotillomania. ${ }^{44}$ Reducing stress may be accomplished with self-hypnosis ${ }^{45}$ or another of the aforementioned methods.

\section{Urticaria}

Urticaria or hives may be triggered or exacerbated by stress. ${ }^{36}$ The itchy urticaria can in itself be stressful, creating a vicious circle. Stress may be reduced with self-hypnosis ${ }^{46}$ or another of the above-mentioned methods.

\section{Influence of primary psychiatric disorders on skin diseases}

\section{Primary anxiety}

Acute or chronic anxiety can worsen many skin disorders. Having a skin disorder can also induce anxiety in susceptible individuals. In a recent study, $13 \%$ of patients seen at a dermatology clinic had an anxiety disorder. ${ }^{13}$

\section{Psychogenic pruritus}

Psychogenic pruritus or itching initiated or exacerbated by anxiety or psychological trauma or stress should be considered when other causes of pruritus have been ruled out. ${ }^{34}$ Stress and anxiety may be lessened using self-hypnosis ${ }^{27}$ or another of the above-mentioned methods. Anxiety may also be treated with anxiolytics. ${ }^{14}$

\section{Delusions}

\section{Delusions of parasitosis}

Delusions of parasitosis occur when the patient insists that they have bugs growing in or on their skin when objectively they do not. This is one of the monomaniacal delusions. Compliant patients generally respond to typical antipsychotics such as pimozide or atypical antipsychotics such as olanzapine or risperidone. Parenterally administered risperidone was found to be particularly effective, since this route of administration had built-in monitoring of compliance. $^{47}$

\section{Primary depression}

Depression and risk of self-harm or suicide can occur as a primary process or secondary to a skin disease. Primary depression may also be associated with acts that self-harm the skin such as scratching, picking, digging, burning, cutting, pulling, tearing, or otherwise harming the skin, hair, or nails. ${ }^{48}$ In a recent study, $32 \%$ of patients seen at a dermatology clinic had depression. ${ }^{13}$ The majority of patients who have self-inflicted dermatoses such as neurotic or psychogenic excoriations suffer from depression with somatization. ${ }^{49}$ Treating the depression with an antidepressant ${ }^{14}$ may help to reduce or eliminate the self-damaging habit.

\section{Impulse control}

\section{Acne excoriée}

Some patients who pick at their acne excessively are primarily impulsive in their picking. Along with standard treatments for the acne, reducing or stopping the picking habit is necessary. Cognitive-behavioral methods or hypnosis and self-hypnosis ${ }^{50}$ may be used. If these measures fail, hypnoanalysis may be considered.

\section{Neurodermatitis}

Some neurodermatitis patients are primarily impulsive in their picking. ${ }^{51}$ Cognitive--behavioral methods ${ }^{52}$ or hypnosis and self-hypnosis ${ }^{27}$ may be of benefit. For resistant cases, hypnoanalysis may be employed.

\section{Trichotillomania}

Trichotillomania is currently classified as an impulse control disorder. ${ }^{44}$ Cognitive-behavioral methods may be beneficial. ${ }^{53}$ Hypnoanalysis may help deal with root causes in refractory cases.

\section{Obsessive-compulsive disorder}

Obsessive-compulsive disorder spectrum patterns may be a primary factor in producing skin disease or in exacerbating a pre-existing skin disease such as acne, atopic dermatitis, or psoriasis. In a recent study, about $5 \%$ of patients evaluated at a dermatology clinic had obsessive-compulsive disorder. ${ }^{13}$ 


\section{Acne excoriée}

Some acne excoriators are primarily obsessive-compulsive in their picking. ${ }^{50}$ Cognitive-behavioral methods may be helpful, as may selective serotonin reuptake inhibitor (SSRI) antidepressants. ${ }^{54}$ Hypnosis with pattern-interrupt suggestions may also be of benefit.

\section{Onychotillomania}

Onychotillomania is compulsive manipulation causing damage to nails. It may be a form of obsessive-compulsive disorder. ${ }^{55}$ Cognitive-behavioral methods may be of benefit, as may SSRI antidepressants. ${ }^{54}$ Hypnosis with pattern-interrupt suggestions may also help.

\section{Neurodermatitis}

Some patients with neurodermatitis or psychogenic excoriations fit best into the obsessive-compulsive category. ${ }^{49}$ Cognitive-behavioral methods may be of benefit, as may SSRI antidepressants. ${ }^{54}$ In some patients, hypnosis with patterninterrupt suggestions may be effective. In unresponsive cases, hypnoanalysis may be considered.

\section{Somatization with dissociation}

Unexplainable bodily symptoms that have no underlying physical pathology are common both in general medicine and in dermatology. Common somatization with dissociation syndromes in general medicine include chronic fatigue syndrome, fibromyalgia, irritable bowel syndrome, and interstitial cystitis. ${ }^{56}$ In dermatology, somatization with dissociation syndromes include unexplained cutaneous sensory syndromes (see below), body memories from traumatic stress in post traumatic stress syndrome (PTSD) that manifest as pruritus, urticaria, or angioedema, self-induced dermatitis artifacta and trichotillomania associated with dissociative states, and body dysmorphic disorder, where the patient has a distorted somatic preoccupation involving the skin or hair. ${ }^{49}$ Among acne patients, $14 \%$ to $21 \%$ have aspects of body dysmorphic disorder. ${ }^{57}$ Nihilodermia refers to problem patients without objective skin findings but who have recurrent symptoms and are insistent on medical examination and treatment. ${ }^{58}$ Alexithymia is associated with somatization with dissociation and is characterized by difficulty in recognizing and describing feelings. ${ }^{59}$ As a general rule, functional somatic syndromes seem more responsive to active non-drug treatments requiring active patient participation, such as exercise and psychotherapy compared with passive physical procedures and injections. Also, drugs that have a central nervous system action generally are more effective than those that affect peripheral physiologic function. ${ }^{60}$ If antidepressant treatment alone is ineffective, adding pregabalin may result in improvement. ${ }^{61}$

\section{Neurogenic cutaneous sensory dysesthesias Dysesthesias arising in the central nervous system}

Generalized pruritus or itching without any visible skin eruption can be due to metabolic, renal, thyroid, hematologic, and other internal diseases. After ruling these out, central nervous system dysfunction as the source of neurogenic pruritus should be considered. One example is pruritus associated with neurotic excoriations. ${ }^{62}$ Another example is otherwise unexplained pruritus associated with somatization with dissociation. ${ }^{63}$ Sedating antihistamines such as hydroxyzine or doxepin have some antipruritic effect, as may some opiate agonists, but for neurogenic pruritus there is no really potent antipruritic drug.

\section{Dysesthesias arising in the peripheral nervous system}

\section{Brachioradial pruritus}

Brachioradial pruritus or itching of the arm, antecubital fossa, and proximal forearm tends to occur in lightly pigmented individuals who have had extensive chronic sun exposure. ${ }^{64}$ This generally is more prominent during the summer. In some patients, peripheral neuropathic pruritus associated with cervical spinal foramen nerve impingement may be the etiologic factor. ${ }^{65}$ Relief from the pruritus may be obtained by sun protection, topical menthol, topical capsaicin, or oral gabapentin.

\section{Glossodynia}

After organic factors for tongue pain such as vitamin deficiency are ruled out, treatment of glossodynia is symptomatic with topical anesthetics. In some cases, oral gabapentin or oral olanzapine may be useful. ${ }^{66}$

\section{Notalgia paresthetica}

Notalgia paresthetica is a peripheral neuropathic pruritus of the medial subscapular shoulder blade area that, at least in some cases, may relate to nerve impingement in a thoracic spinal foramen. ${ }^{67}$ The topical antipruritics, menthol or capsaicin, may offer relief, as may oral gabapentin. ${ }^{67}$

\section{Postherpetic neuralgia}

Postherpetic neuralgia is a peripheral neuropathic pruritus, pain, or paraesthesia following herpes zoster (shingles). 
It occurs more frequently in individuals older that 60 . Topical treatment with capsaicin four or five times a day, which depletes substance $\mathrm{P}$ in the nerves, may be useful. Oral gabapentin also may help reduce the neuropathic sensations. ${ }^{68}$ Acupuncture and hypnosis ${ }^{27}$ for pain or pruritus have provided relief in some patients.

\section{Pruritus ani, pruritus scroti, and pruritus vulvae}

Organic factors such as pinworms, candidal and fungal infections, and inflammatory skin diseases should be ruled out first. The source of the pruritus ani, pruritus scroti, or pruritus vulvae may be peripheral neuropathic as a result of sacral nerve impingement ${ }^{69}$ or may be psychogenic. Topical pramoxine and hydrocortisone may offer relief for some patients. Oral antihistamines may benefit some patients. ${ }^{70}$

\section{Secondary psychiatric disorders associated with skin diseases}

Around $30 \%$ of patients with skin disorders are reported to have psychiatric disorders and psychosocial impairments. ${ }^{71}$ The overall prevalence of psychological disorders among patients with skin disease is about $25 \%$ to $30 \%$, but even higher prevalence rates, above $30 \%$, occur among patients with acne, alopecia, herpes simplex pruritus, and urticaria. ${ }^{72}$ Skin disease with associated psychological morbidity results in poorer quality of life than just having the skin disease alone. ${ }^{73}$

\section{Secondary anxiety}

\section{Acne}

In susceptible individuals, acne can lower self-esteem, self-confidence, cause embarrassment, and impair social functioning. In anxiety-prone individuals, acne can also increase anxiety substantially. The added stress and anxiety can cause acne to flare, creating a vicious cycle. ${ }^{74}$ Drug treatments for anxiety include a low-dose benzodiazepine monitored carefully, buspirone, or herbal anxiolytics, such as magnolia bark or passion flower. Relaxation techniques, self-hypnosis, or biofeedback for relaxation can enhance treatment of anxiety without the side effects of drugs.

\section{Urticaria}

Urticaria or hives with release of pruritus-inducing histamine can induce anxiety in anxiety-prone individuals. The anxiety can in turn flare the urticaria, creating a vicious cycle. ${ }^{36}$ The antihistamines diphenhydramine, doxepin, and hydroxyzine are sedating and can reduce anxiety while also reducing the urticaria through their antihistaminic effect.

\section{Secondary depression}

For each of the conditions below, patients with major depression should be referred to a psychiatrist for care. SSRIs or tricyclics may be prescribed for minor depression, ${ }^{14}$ or the herb St. John's wort may be recommended. Cognitive-behavioral therapy may also be helpful for depression.

\section{Acne}

Acne usually begins in puberty in conjunction with sex hormone changes. Adolescent patients with severe acne had a prevalence of depression of about $18 \%$ to $29 \%$, compared with a prevalence of depression of about $5 \%$ to $8 \%$ for the general adolescent population. ${ }^{75}$ Depressive symptoms are often concealed, denied or expressed through aggressive or disruptive behavior in adolescents. A more severe form of acne, nodulocystic acne, often persists late into adulthood. Oral isotretinoin used to treat nodulocystic acne has been questionably associated with increased depression and suicide. $^{76}$

\section{Alopecia}

Hair loss may occur with androgenetic (male pattern) alopecia, alopecia areata (patchy hair loss), scarring from discoid lupus or lichen planopilaris, telogen effluvium (diffuse hair loss), hypothyroidism, as a side effects of drugs, especially cancer chemotherapy drugs, or as a result of behavior such as trichotillomania or traction alopecia. Hair appearance can affect psychosocial functioning. In susceptible individuals, hair loss can induce or exacerbate depression. Alopecia areata can worsen with depression. ${ }^{16}$

\section{Atopic dermatitis}

The pruritus or itching of atopic dermatitis can aggravate depression in depression-prone individuals, who then often scratch more and worsen their skin disorder. ${ }^{77}$ The antihistamines diphenhydramine, hydroxyzine, and doxepin cause sedation and can reduce pruritus and scratching through their antihistaminic effect. Doxepin is also a tricyclic antidepressant. Individuals with major depression should be referred to a psychiatrist for care. Self-hypnosis with suggestions for soothing can reduce pruritus or itching and give the patient a sense of greater control, which in turn can improve the depression.

\section{Disfigurement}

Disfigurement secondary to skin disorders, traumatic injuries, ${ }^{78}$ and surgeries for skin cancers can aggravate depression in depression-prone individuals. Hypnosis and reframing 
can alter the patient's perspective on their disfigurement, secondarily reducing depression.

\section{Malignant melanoma}

Metastatic melanoma often has a grim prognosis and can induce situational depression, which in turn degrades the body's immune response ${ }^{79}$ against the melanoma metastases. Treatment of the depression may enhance the body's ability to respond against the melanoma.

\section{Psoriasis}

In depression-prone individuals, psoriasis can initiate or exacerbate depression, which in turn can enhance the sensation of pruritus. ${ }^{77}$ Injuring the skin by scratching psoriatic plaques can exacerbate the psoriasis. Self-hypnosis can reduce pruritus or itching and give a sense of greater self-control, which in turn can lessen the depression.

\section{Urticaria}

In depression-prone individuals, chronic urticaria can initiate or exacerbate depression which can in turn exacerbate pruritus. ${ }^{77}$ Self-hypnosis can reduce pruritus or itching and give a sense of greater self-control, which can lessen the depression. Hypnosis has resolved some cases of chronic urticaria. $^{25}$

\section{Vitiligo}

In depression-prone individuals, vitiligo can initiate or exacerbate depression, especially in darkly pigmented individuals. ${ }^{80}$ The prevalence of depression in vitiligo patients was 39\% in a recent quality of life study. ${ }^{81}$ Cognitive-behavioral therapy may help reduce the depression. ${ }^{82}$ Hypnosis can also help to reframe the patient's perspective on their depigmented lesions, lessening secondary depression.

\section{Therapeutic options Conventional pharmacologic psychocutaneous therapies}

For the most current information on specific products, check the current Physicians' Desk Reference, ${ }^{83}$ package inserts, or other appropriate information source to ascertain dosages, indications and usage, review pharmacokinetics, and note contraindications, warnings, precautions, drug interactions, and adverse reactions. Many psychotropic drugs should be started at a low dose and progressively increased to therapeutic range, then tapered as appropriate. ${ }^{14}$ Dosages given in the tables are for the average healthy young or middle-aged adult. Lower initial dosages are recommended in the elderly because of slower renal and/or hepatic clearance.

\section{Antidepressants}

SSRIs are used in dermatology to treat depression, anxiety, and obsessive-compulsive spectrum disorders associated with skin diseases. Side effects of SSRIs include nausea, diarrhea, insomnia, or sedation. ${ }^{14}$ SSRIs should be started at low dose and titrated upward. Onset of effects of SSRIs is slow, usually taking three to six weeks (see Table 1).

Tricylic antidepressants are also used in dermatology for depression and obsessive-compulsive spectrum disorders (see Table 1). Doxepin, which also has antihistaminic properties, is the tricyclic most commonly prescribed by dermatologists. The norepinephrine and dopamine reuptake inhibitor bupropion, an aminoketone antidepressant, is less commonly used (see Table 1).

\section{Antipsychotics}

Typical (dopamine receptor antagonist) antipsychotics are used in dermatology for delusional psychoses such as delusions of parasitosis, delusions of bromhidrosis, and Morgellons delusions of fibers (see Table 2). Atypical (serotonin-dopamine antagonist) antipsychotics are often used in dermatology for treatment of resistant cases of obsessive-compulsive spectrum disorders, as a second agent in addition to SSRIs (see Table 2).

\section{Anticonvulsants}

Gamma aminobutyric acid (GABA) elevators are used in dermatology for relief of pain, itching, or paraesthesias in peripheral neuropathies including postherpetic neuralgia (see Table 2).

\section{Anxiolytics}

Benzodiazapines are Schedule IV controlled substances because of their potential for abuse and addictive dependence. They tend to be sedating. In dermatology, they are used for preprocedure anxiety. Generally the short-acting benzodiazapines are preferable for this purpose (see Table 3).

The serotonin agonist buspirone is an azaperone. Its advantages are that it is not a controlled substance and is nonsedating. Its disadvantage is that it has a delayed onset of action of about two weeks (see Table 3).

\section{Sedatives}

Sedating antihistamines are used extensively in dermatology for pruritus, angioedema, dermatographism, and urticaria. 
Table I Antidepressants used in dermatologic conditions

\begin{tabular}{|c|c|c|c|c|}
\hline Category & Agent & Dosage & Side effects & Cautions \\
\hline \multirow[t]{7}{*}{$\overline{\text { SSRI }}$} & Citalopram $\left(\right.$ Celexa $\left.^{\circledR}\right)$ & $20-40 \mathrm{mg}$ daily & Sedation & SSRIs slow \\
\hline & Escitalopram (Lexapro ${ }^{\circledR}$ ) & $10 \mathrm{mg}$ daily & & onset of effect \\
\hline & Fluoxetine $\left(\operatorname{Prozac}^{\circledR}\right)$ & $20-80 \mathrm{mg}$ daily & Insomnia & Taper off slowly \\
\hline & Fluvoxamine $\left(\right.$ Luvox $\left.^{\circledR}\right)$ & $25-150 \mathrm{mg}$ bid & Gl symptoms & Multiple drug \\
\hline & Paroxetine $\left(\right.$ Paxil $\left.^{\circledR}\right)$ & $20-50 \mathrm{mg}$ daily & Sedation & Interactions \\
\hline & Sertraline $\left(\right.$ Zoloft $\left.^{\circledR}\right)$ & $25-200 \mathrm{mg}$ daily & Gl symptoms & \\
\hline & Venlafaxine $\left(\right.$ Effexor $\left.^{\circledast}\right)$ & $25-75 \mathrm{mg}$ tid & & \\
\hline \multirow[t]{7}{*}{ Tricyclic } & Amitriptyline $\left(\right.$ Elavi $\left.^{\circledR}\right)$ & $25-50 \mathrm{mg}$ daily & Sedation, dry mouth & Tricyclics \\
\hline & Clomipramine $\left(\right.$ Anafranil $\left.{ }^{\circledR}\right)$ & $25-250 \mathrm{mg}$ daily & Sedation, dry mouth & Risk of seizures \\
\hline & Doxepin $\left(\right.$ Sinequan ${ }^{\circledR}$ ) & $25-300 \mathrm{mg}$ daily & Sedation & \\
\hline & Imipramine $\left(\right.$ Tofranil $\left.^{\circledR}\right)$ & 25-300 mg daily & Orthostatic hypotension & $\begin{array}{l}\text { Heart } \\
\text { dysconduction }\end{array}$ \\
\hline & Nortriptyline $\left(\right.$ Pamelor $\left.^{\circledR}\right)$ & $25-150 \mathrm{mg}$ daily & Dry mouth & \\
\hline & Protryptyline $\left(\right.$ Vivacti $\left.^{\circledR}\right)$ & $5-20 \mathrm{mg}$ tid & Dry mouth & \\
\hline & Trimipramine (Surmontil ${ }^{\circledR}$ ) & $5-50 \mathrm{mg}$ tid & Sedation & \\
\hline NE/DUI & Bupropion (Welbutrin ${ }^{\circledast}$ ) & $75-150 \mathrm{mg}$ bid & & \\
\hline Herbs & St. John's wort & $300-1200$ mg daily & Photosensitivity & Drug interactions \\
\hline Supplement & SAMe & $200-800 \mathrm{mg}$ bid & & \\
\hline \multirow[t]{2}{*}{ Non-drug } & Exercise & Daily & & \\
\hline & Hypnosis & Daily & & \\
\hline
\end{tabular}

Abbreviations: bid, twice daily; GI, gastrointestinal; SSRI, selective serotonin reuptake inhibitor; NE/DUI, norepinephrine and dopamine reuptake inhibitor; SAMe, S-adenosulL-methionine; tid, three times daily.

Hydroxyzine and promethazine are also mildly to moderately anxiolytic. In addition, doxepin has antidepressant properties (see Table 4).

\section{Antipruritics}

While no really effective antipruritic drugs have been developed, sedating antihistamines may be helpful (see Table 4). Topical antipruritics may also offer relief (see Table 5).

\section{Complementary pharmacological psychocutaneous therapies Herbs and supplements}

Herbal therapy in dermatology was reviewed by Bedi and Shenefelt ${ }^{84}$ and use of herbs and supplements in dermatology by Levin and Maibach. ${ }^{85}$ Further information about individual herbs, their actions, interactions, and adverse effects is available in the PDR for Nonprescription Drugs,

Table 2 Antipsychotics and anticonvulsants used in dermatologic conditions

\begin{tabular}{|c|c|c|c|c|}
\hline Category & Agent & Dosage & Side effects & Cautions \\
\hline \multicolumn{5}{|c|}{ Antipsychotics } \\
\hline \multirow[t]{4}{*}{ Typical } & Haloperidol $\left(\right.$ Haldol $\left.^{\circledR}\right)$ & 5-20 mg daily acutely & Tardive dyskinesia & Mild sedation \\
\hline & & Maintenance $\mathrm{I}-10 \mathrm{mg}$ daily & & \\
\hline & Pimozide (Orap ${ }^{\circledR}$ ) & $0.5-10 \mathrm{mg}$ daily acutely & Tardive dyskinesia & \\
\hline & & Maintenance $0.5-5 \mathrm{mg}$ daily & & \\
\hline \multirow[t]{3}{*}{ Atypical } & Olanzapine (Zyprexa $\left.{ }^{\circledR}\right)$ & $2.5-10 \mathrm{mg}$ daily & Weight gain & Diabetes \\
\hline & Risperidone (Risperda ${ }^{\circledR}$ ) & $\mathrm{I}-3 \mathrm{mg}$ daily & & \\
\hline & Ziprasidone $\left(\right.$ Geodon $\left.^{\circledR}\right)$ & $20-100 \mathrm{mg}$ bid & & \\
\hline \multicolumn{5}{|c|}{ Anticonvulsants } \\
\hline \multirow[t]{2}{*}{ GABA } & Gabapentin (Neurontin ${ }^{\circledR}$ ) & $100-600 \mathrm{mg}$ tid & & \\
\hline & Pregabalin $\left(\right.$ Lyrica $\left.^{\circledR}\right)$ & $50-100 \mathrm{mg}$ tid & & \\
\hline
\end{tabular}

Abbreviations: bid, twice daily; GABA, gamma amino butyric acid; tid, three times daily. 
Table 3 Anxiolytics used in dermatologic conditions

\begin{tabular}{lllll}
\hline Category & Agent & Dosage & Side effects & Cautions \\
\hline Benzodiazepines & Alazopram (Xanax) & $0.25-0.5 \mathrm{mg}$ tid & Short-acting sedation & Use caution \\
& Lorazepam (Ativan) & $1 \mathrm{mg}$ bid-tid & Short-acting sedation & Driving \\
Azaperone & Diazepam (Valium) & $2-10 \mathrm{mg}$ bid-qid & Long-acting sedation & With each \\
Herbs & Buspirone (Buspar) & $5-30 \mathrm{mg}$ bid & Very slow acting & \\
& Magnolia bark & $250-750 \mathrm{mg}$ daily & & \\
Passion flower & $0.5-1 \mathrm{ml}$ fluid extract & & Avoid use driving \\
& Biofeedback & Daily-tid & & Avoid use driving \\
& Cognitive-behavioral & Daily and prn & & \\
& Hypnosis & Daily & & \\
& Meditation & Daily and prn & & \\
& Placebo & Daily and prn & & \\
& Suggestion & Prn & \\
& Yoga & Prn & & \\
\end{tabular}

Abbreviations: bid, twice daily; Prn, per required need; tid, three times daily.

Dietary Supplements and Herbs ${ }^{86}$ The Complete German Commission E Monographs, ${ }^{87}$ and in many other textbooks and monographs. Psychoactive herbs and supplements that may have some indirect impact on skin diseases through anxiolytic, antidepressant, or soporific activities are of particular interest in psychosomatic dermatology. Herbal therapy in psychiatry was reviewed by Sarris. ${ }^{88}$ See the current PDR for Nonprescription Drugs, Dietary Supplements and Herbs for details of their actions, interactions, adverse effects, and literature references.

\section{Antidepressants}

Saint John's wort is approved by the German Commission E for depression. It is helpful in mild to moderate depression but not for severe depression. ${ }^{89}$ It induces cytochrome P450 which changes the metabolism of a number of other drugs.
S-adenosyl-L-methionine (SAMe) is also taken as an antidepressant. A meta-analysis of studies comparing SAMe with controls showed significant clinical improvement with SAMe similar to that of standard SSRI treatment, with fewer side effects $^{90}$ (see Table 1).

\section{Anxiolytics}

Aromatherapy with lavender oil has been shown to produce a significant reduction in anxiety. Lemon balm has been approved by the German Commission E for nervousness and insomnia. Kava kava has moderate anxiolytic effects, but its use is not recommended because of its potential hepatotoxicity. Magnolia bark has moderate anxiolytic effects ${ }^{91}$ and has been used in Japan for a number of years. Passion flower has been approved by the German Commission E for nervousness and insomnia (see Table 3 ).

Table 4 Sedatives used in dermatologic conditions

\begin{tabular}{lllll}
\hline Category & Agent & Dosage & Side effects & Cautions \\
\hline Antihistamines & Certirizine $\left(\right.$ Zyrtec $\left.^{\circledR}\right)$ & $10 \mathrm{mg}$ daily & Sedative & Use caution driving \\
& Diphenhydramine $\left(\right.$ Benadry $\left.^{\circledR}\right)$ & $25-50 \mathrm{mg}$ tid-qid & Sedative & With each \\
& Doxepin $\left(\right.$ Sinequan $\left.{ }^{\circledR}\right)$ & $25-100 \mathrm{mg}$ tid & Sedative & Sedative \\
& Hydroxyzine $\left(\right.$ Atarax $\left.^{\circledR}\right)$ & $25-100 \mathrm{mg}$ tid & Mild sedative \\
& Levocetrizine $\left(\right.$ Xyza $\left.^{\circledR}\right)$ & $5 \mathrm{mg}$ daily & Sedative & \\
Herbs & Promethazine $\left(\right.$ Phenergan $\left.^{\circledR}\right)$ & $25-100 \mathrm{mg}$ tid-qid & & Avoid use driving \\
Supplements & Valerian & $300-900 \mathrm{mg}$ daily HS & & \\
Nondrug & Melatonin & $3 \mathrm{mg} \mathrm{HS}$ & & \\
& Hypnosis & $\mathrm{HS}$ & & \\
\hline
\end{tabular}

Abbreviations: HS, at bedtime; qid, four times daily; tid, three times daily. 
Table 5 Antipruritics used in dermatologic conditions

\begin{tabular}{lllll}
\hline Category & Agent & Dosage & Side effects & Cautions \\
\hline Herbs & Capsaicin & Topical qid & $\begin{array}{l}\text { Burning } \\
\text { sensation }\end{array}$ & $\begin{array}{l}\text { Avoid } \\
\text { eyes }\end{array}$ \\
& Camphor & Topical prn & & \\
& Menthol & Topical prn & & $\begin{array}{l}\text { Avoid use } \\
\text { Nondrug }\end{array}$ \\
& Hypnosis & Daily and prn & & driving \\
\hline
\end{tabular}

Abbreviations: Prn, per required need; qid, four times daily.

\section{Soporifics}

Melatonin can produce drowsiness. When it is taken, caution should be used in operating machinery. Valerian has been approved by the German Commission E for insomnia caused by nervousness (see Table 4).

\section{Nonpharmacologic treatments for psychocutaneous disorders}

\section{Placebo and nocebo}

Expectation forms the basis for the placebo effect. The use of placebo remains controversial. ${ }^{92,93}$ The patient expectations, the doctor's expectations, and the doctor-patient relationship can affect the patient's experience of treatment, reduce pain, and influence outcome. While positive expectations or suggestions can produce positive placebo results, negative expectations or suggestions can produce negative nocebo results. ${ }^{94}$ Research on the placebo effect illustrates the extent to which the natural healing capacities of individuals can be enhanced and nurtured..$^{95}$ In some common dermatologic conditions, such as acne and urticaria, the placebo effect is about 30\%. ${ }^{96}$ Those skin disorders higher on the Griesemer scale ${ }^{67}$ are more likely to have a significant placebo effect.

\section{Suggestion}

Suggestion is the effect that words, intonation, and/or nonverbal cues have by association that can be used to change subjective perceptions, reduce pain, and influence outcome. Suggestion has been used to promote healing since antiquity. Bloch $^{97}$ and Sulzberger and Wolf ${ }^{98}$ reported on the efficacy of suggestion in treating verruca vulgaris (warts), and that efficacy has since been confirmed numerous times to a greater or lesser degree, ${ }^{99-102}$ but failed to be confirmed in a few studies. ${ }^{103,104}$ A recent study that showed negative results was criticized for using a negative suggestion of not feeding the warts rather than a positive suggestion about having the warts resolve. ${ }^{105}$

\section{Cognitive-behavioral methods}

Cognitive-behavioral methods alter dysfunctional habits by interrupting and altering dysfunctional thought patterns (cognitions) or actions (behaviors) ${ }^{106}$ that damage the skin or interfere with dermatologic therapy. Skin diseases responsive to cognitive-behavioral methods include acne excoriée, atopic dermatitis, factitious cheilitis, hyperhidrosis, lichen simplex chronicus, needle phobia, neurodermatitis, onychotillomania, prurigo nodularis, trichotillomania, and urticaria. Adding hypnosis to cognitive-behavioral therapy can facilitate aversive therapy and enhance desensitization and other cognitive-behavioral methods. ${ }^{107}$

\section{Biofeedback}

Biofeedback can enhance the patient's awareness of tension and help them to relax, improving skin disorders that flare with stress or that have an autonomic nervous system aspect. Biofeedback of GSR can help reduce hyperhidrosis (excess sweating). Biofeedback of skin temperature by temperaturesensitive strip or by thermocouple can be used for relaxation, ${ }^{9}$ dyshidrosis, and Raynaud's syndrome. ${ }^{108-110}$ HRV biofeedback can also help reduce the stress response that tends to exacerbate many inflammatory skin disorders. Hypnosis can produce relaxation and enhance the effects produced by biofeedback. ${ }^{107}$

\section{Hypnosis}

Hypnosis has many useful dermatologic applications. Medical hypnotherapy involves guiding the patient into a trance state of narrowed awareness, focused attention, selective wakefulness, and heightened suggestibility for a specific purpose such as relaxation, pain or pruritus reduction, or habit modification. The hypnotic trance compared with the usual waking state has objectively documented differences in regional cerebral blood flow ${ }^{111}$ and $\mathrm{EEG}^{112}$ patterns. One way that hypnosis may make suggestions more effective is by inhibiting competing thoughts so that the focus can be solely on the suggestion. ${ }^{113}$ Hypnosis may improve or clear numerous skin disorders. Examples include acne excoriée, alopecia areata, atopic dermatitis, congenital ichthyosiform erythroderma, dyshidrotic dermatitis, erythromelalgia, furuncles, glossodynia, herpes simplex, hyperhidrosis, ichthyosis vulgaris, lichen planus, neurodermatitis, nummular dermatitis, post-herpetic neuralgia, pruritus, psoriasis, rosacea, trichotillomania, urticaria, verruca vulgaris, and vitiligo. ${ }^{7}$ Generally, high and medium hypnotizables respond better than low hypnotizables, although for many purposes light trance is all that is necessary. Dermatologists should generally not use hypnosis with schizophrenics or others who are not 
mentally intact. Hypnosis also can reduce anxiety and pain associated with dermatologic procedures. Hypnoanalysis has been successful with reducing erythema nodosum, herpes simplex reactivation, neurodermatitis, neurotic excoriations, rosacea, urticaria, and verrucae (viral warts) ${ }^{25}$

\section{Conclusion}

Skin disorders that produce changes in the appearance of skin, hair, or nails, or changes in sensation can have a major impact on the psyche. Treating the skin disorder effectively often induces psychosocial improvement. The psyche through psychoneuroimmunoendocrine and behavioral mechanisms can in turn have a major impact on skin disorders. Treating the psyche effectively can improve many inflammatory skin disorders. The psychotropic drugs listed above are often somewhat effective by themselves. Adding non-drug psychocutaneous modalities such as biofeedback, cognitive-behavioral methods, hypnosis, or suggestion often synergistically enhance the treatment response. Teaching patients to practice safe stress using these nonpharmacologic methods, supplemented if necessary with anxiolytic standard drugs or herbal alternatives, is important, since many inflammatory skin disorders are worsened by stress. Exercise, meditation, music therapy, progressive relaxation, self-hypnosis, and other stress-reducing methods can enhance overall health and resiliency, as well as achieving improvement in specific skin disorders.

\section{Disclosure}

The author reports no conflicts of interest in this work.

\section{References}

1. Zane LT. Psychoneuroendocrinimmunodermatology: Pathophysiological mechanisms of stress in cutaneous disease. In: Psychocutaneous Medicine, Koo JYM, Lee CS, editors. New York, NY: Marcel Dekker; 2003. p. 65-95.

2. Harth W, Gieler U, Kunir D, Tausk FA. Clinical Management in Psychodermatology. Berlin, AG: Springer Verlag; 2009:195-208.

3. Fried RG. Nonpharmacologic treatments in psychodermatology. Dermatol Clin. 2002;20:177-185.

4. Jaffarany M. Psychodermatology: A guide to understanding common psychocutaneous disorders. Prim Care Companion J Clin Psychiatry. 2007;9:203-213.

5. Poot F, Sampogna F, Onnis L. Basic knowledge in psychodermatology. J Eur Acad Dermatol Venereol. 2007;21:227-234.

6. Griesemer RD. Emotionally triggered disease in a dermatological practice. Psychiatr Ann. 1978;8:49-56.

7. Shenefelt PD. Hypnosis in dermatology. Arch Dermatol. 2000; 136:393-399.

8. Urpe M, Buggiani G, Lotti T. Stress and psychoneuroimmunologic factors in dermatology. Dermatol Clin. 2005;23:609-617.

9. Shenefelt PD. Relaxation, meditation, and hypnosis for skin disorders and procedures. In: deLuca BN, editor. Mind-Body and Relaxation Research Focus. Hauppauge, NY: Nova Science Publishers; 2008. p. 45-63.

10. Barrios AA. Towards Greater Freedom and Happiness. 3rd ed. Culver City, CA: Self-Programmed Control Press; 1985.
11. Zucker TL, Samuelson KW, Muench F, Greenberg MA, Gevirtz RN. The effects of respiratory sinus arrhythmia biofeedback on heart rate variability and posttraumatic stress disorder symptoms: A pilot study. Appl Psychophysiol Biofeedback. 2009;34:135-143.

12. Panconesi E. Psychosomatic factors in dermatology: Special perspectives for application in clinical practice. Dermatol Clin. 2005;23: 629-633.

13. Seyhan M, Aki T, Karincaoglu Y, Ozcan H. Psychiatric morbidity in dermatology patients: Frequency and results of consultations. Indian J Dermatol. 2006;51:18-22.

14. Lee CS, Koo JYM. The use of psychotropic medications in dermatology. In: Koo JYM, Lee CS, editors. Psychocutaneous Medicine. New York, NY: Marcel Dekker; 2003. p. 427-451.

15. Lucky AW. Quantitative documentation of a premenstrual flare of facial acne in adult women. Arch Dermatol. 2004;140:42-44.

16. Hughes H, Brown BW, Lawlis GF, Fulton JE. Treatment of acne vulgaris by biofeedback relaxation and cognitive imagery. J Psychosom Res. 1983;27:185-191.

17. Willemson R, Haentjens P, Roseeuw D, Vanderlinden J. Alexithymia in patients with alopecia areata: Educational background much more important than traumatic events. J Eur Acad Dermatol Venereol. 2009;23:1141-1146.

18. Gupta MA, Gupta AK, Watteel GN. Stress and alopecia areata: A psychodermatologic study. Acta Derm Venereol Stockholm. 1997;77: 296-298.

19. Willemsen R, Vanderlinden J, Deconinck A, Roseeuw D. Hypnotherapeutic management of alopecia areata. J Am Acad Dermatol. 2006;55:233-237.

20. Pallanti S, Lotti T, Urpe M. Psychoneuroimmunodermatology of atopic dermatitis: From empiric data to the evolutionary hypothesis. Dermatol Clin. 2005;23:695-701.

21. Ehlers A, Stangler U, Gieler U. Treatment of atopic dermatitis: A comparison of psychological and dermatological approaches to relapse prevention. J Consult Clin Psychol. 1995;63:624-635.

22. Stewart AC, Thomas SE. Hypnotherapy as a treatment for atopic dermatitis in adults and children. Brit J Dermatol. 1995;132:778-783.

23. Koblenzer CS. Dermatitis artifacta: Clinical features and approaches to treatment. Am J Clin Dermatol. 2000;4:161-163.

24. Koldys KW, Meyer RP. Biofeedback training in the therapy of dyshidrosis. Cutis. 1979;24:219-221.

25. Shenefelt PD. Psychocutaneous hypnoanalysis: Detection and deactivation of emotional and mental root factors in psychosomatic skin disorders. Am J Clin Hypn. 2007;50:131-136.

26. Buske-Kirchenbaum A, Geiben A, Wermke C, et al. Preliminary evidence for herpes labialis recurrence following experimentally induced disgust. Psychother Psychosom. 2001;70:86-91.

27. Scott MJ. Hypnosis in Skin and Allergic Diseases. Springfield, IL: Charles C. Thomas Publishers; 1960.

28. Lowe NJ, Glaser DA, Eadie N, Daggett S, Kowalski JW, Lai PY. Botulinum toxin type $\mathrm{A}$ in the treatment of primary axillary hyperhidrosis: A 52 week multicenter double-blind, randomized, placebo-controlled study of efficacy and safety. J Am Acad Dermatol. 2007;56:604-611.

29. Hölzle E. Therapie der hyperhidrosis. Hautarzt. 1994;35:7-15. German.

30. Koray M, Dulger O, Ak G, et al. The evaluation of anxiety and salivary cortisol levels in patients with oral lichen planus. Oral Dis. 2003;9:298-301.

31. Konuk N, Koca R, Atik L, Muhtar S, Atasoy N, Bostanci B. Psychopathology, depression and dissociative experiences in patients with lichen simplex chronicus. Gen Hosp Psychiatry. 2007;29:232-235.

32. Ko SM. Underdiagnosed psychiatric syndrome, 2: Pathologic skin picking. Ann Acad Med Singapore. 1999;28:557-559.

33. Lehman RE. Brief hypnotherapy of neurodermatitis: A case with four-year follow-up. Am J Clin Hypn. 1978;21:48-51.

34. Jarvikallio A, Harvima IT, Naukkarinen A. Mast cells, nerves and neuropeptides in atopic dermatitis and nummular eczema. Arch Dermatol Res. 2003;295:1-7. 
35. Guarneri F, Marini H. An unusual case of perioral dermatitis: Possible pathogenic role of neurogenic inflammation. J Eur Acad Dermatol Venereol. 2007;21:410-412.

36. Arck P, Paus R. From the brain-skin connection: The neuroendocrineimmune misalliance of stress and itch. Neuroimmunomodulation. 2006; $13: 347-356$

37. Griffiths CE, Richards HL. Psychological influence in psoriasis. Clin Exp Dermatol. 2001;26:338-342.

38. Masmoudi J, Maalej I, Masmoudi A, et al. Alexithymie et psoriasis: Etude cas-temoin a propos de 53 patients. L'Encephalie. 2009;35:10-17. French.

39. Fortune DG, Richards HL, Kirby B, Bowcock, Main CJ, Griffiths CE. A cognitive-behavioural symptom management programme as an adjunct in psoriasis therapy. Br J Dermatol. 2002;146:458-465.

40. Kabat-Zinn J. Influence of a mindfulness meditation-based stress reduction intervention on rates of skin clearing in patients with moderate to severe psoriasis undergoing phototherapy (UVB) and photochemotherapy (PUVA). Psychosom Med. 1998;60:625-632.

41. Tausk F, Whitmore SE. A pilot study of hypnosis in the treatment of patients with psoriasis. Psychother Psychosom. 1999;68:221-225.

42. Garnis-Jones S. Psychological aspects of rosacea. J Cutan Med Surg. 1998;(Suppl 4):9-16.

43. Sinclair R. Chronic telogen effluvium: A study of 5 patients over 7 years. $J$ Am Acad Dermatol. 2005;52(2 Suppl 1):12-16.

44. Stein DJ, Gardner JP, Keuthen NJ, Franklin ME, Walkup JT, Woods DW. Trichotillomania, stereotypic movement disorder, and related disorders. Curr Psychiatry Rep. 2007;9:301-302.

45. Barabasz M. Trichotillomania: A new treatment. Int J Clin Exp Hypn. 1987;35:146-154.

46. Shertzer CL, Lookingbill DP. Effects of relaxation therapy and hypnotizability in chronic urticaria. Arch Dermatol. 1987;123:913-916.

47. Mercan S, Altunay IK, Taskintuna N, Oguteen O, Kayaoglu S. Atypical antipsychotic drugs in the treatment of delusional parasitosis. Int $J$ Psychiatry Med. 2007;37:29-37.

48. Gupta MA, Gupta AK. Depression and dermatological disorders. In: Koo JYM, Lee CS, editors. Psychocutaneous Medicine. New York, NY: Marcel Dekker; 2003. p. 233-249.

49. Gupta MA. Somatization disorders in dermatology. Int Rev Psychiatry. 2006;18:41-47

50. Shenefelt PD. Using hypnosis to facilitate resolution of psychogenic excoriations in acne excoriée. Am J Clin Hypn. 2004:239-245.

51. Gupta MA, Gupta AK, Haberman HF. Neurotic excoriations: A review and some new perspectives. Compr Psychiatry. 1986;27:381-386.

52. Rosenbaum MS, Ayllon T. The behavioral treatment of neurodermatitis through habit-reversal. Behav Res Ther. 1981;19:313-318.

53. Rothbaum BO, Ninan PT. Manual for the cognitive-behavioral treatment of trichotillomania. In: Stein DJ, Christenson GA, Hollander E, editors. Trichotillomania. Washington, DC: American Psychiatric Publishing; 1999. p. 263-284.

54. Kearney CA, Silverman WK. Treatment of an adolescent with obsessive-compulsive disorder by alternating response prevention and cognitive therapy: An empirical analysis. J Behav Ther Exp Psychiatry. 1990;21:39-47.

55. Inglese M, Haley HR, Elewski BE. Onychotillomania: 2 case reports. Cutis. 2004;73:171-174.

56. Kroenke K, Sharpe M, Sykes R. Revising the classification of somatoform disorders: Key questions and preliminary recommendations. Psychosomatics. 2007;48:277-285.

57. Bowe WP, Leyden JJ, Crerand CE, Sarwer DB, Margolis DJ. Body dysmorphic disorder symptoms among patients with acne vulgaris. J Am Acad Dermatol. 2007;57:222-239.

58. Harth W, Hermes B, Seikowski K, Gieler U. Nihilodermie in der Psychodermatologie. Hautarzt. 2007;58:427-434. German.

59. Willemsen R, Roseeuw D, Vanderlinden J. Alexithymia and dermatology: The state of the art. Int J Dermatol. 2008;47:903-910.

60. Henningsen P, Zipfel S, Herzog W. Management of functional somatic syndromes. Lancet. 2007;369(9565):1691-1692.
61. Harnack D, Scheel M, Mindt A, Kupsch A, Heinz A, Strohle A. Pregabalin in patients with antidepressant treastment-resistant somatiform disorders: A case series. J Clin Psychopharmacol. 2007;27:537-539.

62. Weisshaar E, Kucenic MJ, Fleischer AB. Pruritus: A review. Acta Derm Venereol. 2003;213(Suppl):5-32.

63. Gupta MA, Gupta AK. Medically unexplained cutaneous sensory symptoms may represent somatoform dissociation: An empirical study. J Psychosom Res. 2006;60:131-136.

64. Walcyk PJ, Elpern DJ. Brachioradial pruritus: A tropical dermopathy. Brit J Dermatol. 1986;115:177-180.

65. Goodkin R, Wingard E, Bernhard JD. Brachioradial pruritus: Cervical spine disease and neurogenic/neurogenic pruritus. J Am Acad Dermatol. 2003;48:521-524.

66. Gick CL, Mirowski GW, Kennedy JS, Bymaster FP. Treatment of glossodynia with olanzapine. J Am Acad Dermatol. 2004;51:463-465.

67. Eisenberg E, Bameir E, Bergman R. Notalgia paraesthetica associated with nerve root impingement. J Am Acad Dermatol. 1997;37:998-1000.

68. Eisenberg E, River Y, Shiftrin A, Krivoy N. Antiepileptic drugs in the treatment of neuropathic pain. Drugs. 2007;67:1265-1289.

69. Cohen AD, Vander T, Medvendovsky E, et al. Neuropathic scrotal pruritus: Anogenital pruritus is a symptom of lumbosacral radiculopathy. J Am Acad Dermatol. 2005;52:61-66.

70. Weichert GE. An approach to the treatment of anogenital pruritus. Dermatol Ther. 2004;17:129-133.

71. Kessler RC, Berglund P, Demler O, et al. Lifetime prevalence and ageof-onset distributions of DSM-IV disorders in the National Comorbidity Survey Replication. Arch Gen Psychiatry. 2005;62:593-602.

72. Picardi A, Abenia D, Melchi CF, Puddu P, Pasquini P. Psychiatric morbidity in dermatological outpatients: An issue to be recognized. Brit $J$ Dermatol. 2000;143:983-991.

73. Sampogna F, Picardi A, Chren MM, et al. Association between poorer quality of life and psychiatric morbidity in patients with different dermatological conditions. Psychosom Med. 2004;66:620-624.

74. Schulpis K, Georgala S, Papakonstantinou ED, et al. The psychological and sympatho-adrenal status in patients with cystic acne. J Eur Acad Dermatol Venereol. 1999;13:24-27.

75. Hull PR, D'Arcy C. Acne, depression, and suicide. Dermatol Clin. 2005;23:665-674

76. Wysowski DK, Pitts M, Beitz J. An analysis of reports of depression and suicide in patients treated with isotretinoin. $J$ Am Acad Dermatol. 2001;45:515-519.

77. Gupta MA, Gupta AK, Schork NJ. Depression modulates pruritus perception: A study of pruritus in psoriasis, atopic dermatitis, and chronic idiopathic urticaria. Psychosom Med. 1994;56:36-40.

78. Stoddard FJ, Stroud L, Murphy JM. Depression in children after recovery from severe burns. J Burn Care Rehabil. 1992;13:340-347.

79. Herbert TB, Cohen S. Depression and immunity: A meta-analytic review. Psychol Bull. 1993;113:472-486.

80. Dogra S, Kanawar AJ. Skin diseases: Psychological and social consequences. Indian J Dermatol. 2002;47:197-201.

81. Sampogna F, Raskovic D, Guerra L, et al. Identification of categories at risk for high quality of life impairment in patients with vitiligo. Br J Dermatol. 2008;159:351-359.

82. Papadopoulos L, Bor R, Legg C. Coping with the disfiguring effects of vitiligo: A preliminary investigation into the effects of cognitivebehavioural therapy. Br J Med Psychol. 1999;72:385-396.

83. PDR Staff. 2010 Physician's Desk Reference. 64th ed. Montvale, NJ; 2010.

84. Bedi MK, Shenefelt PD. Herbal therapy in dermatology. Arch Dermatol. 2002;138:232-242.

85. Levin C, Maibach H. Exploration of "alternative" and "natural" drugs in dermatology. Arch Dermatol. 2002;138:207-211.

86. PDR Staff. 2010 PDR for Nonprescription Drugs, Dietary Supplements and Herbs, 31st ed. Montvale, NJ; 2009.

87. Blumenthal M, editor. The Complete German Commission E Monographs: Therapeutic Guide to Herbal Medicines. Austin, TX: American Botanical Council, 1998. 
88. Sarris J. Herbal medicines in the treatment of psychiatric disorders: A systematic review. Phytother Res. 2007;21:703-716.

89. Linde K, Ramirez G, Mulrow C, et al. St. Johns wort for depression: An overview and meta-analysis of randomized clinical trials. BMJ. 1996;313:253-258.

90. Bressa G. S-adenosyl-L-methionine (SAMe) as antidepressant: Metaanalysis of clinical studies. Acta Neurol Scand. 1994;154(Suppl): $7-14$.

91. Kuribara H, Stavinoha WB, Maruyama Y. Behavioral characteristics of honkiol, an anxiolytic agent present in extracts of magnolia bark, evaluated by an elevated plus-maze test in mice. J Pharm Pharmacol. 1998;50:819-826.

92. Hrobjartsson A, Gotzche PC. Is the placebo powerless? An analysis of clinical trials comparing placebo with no treatment. $N$ Eng J Med. 1994;344:1594-1602.

93. Spiegel D, Kraemer H, Carlson RW. Is the placebo powerless? (Letter). N Eng J Med. 2001;345:1276-1279.

94. Speigel D. Placebos in practice (Editorial). BMJ. 2004;329: 927-928.

95. Di Blasi Z, Reilly D. Placebos in medicine: Medical paradoxes need disentangling (Letter). BMJ. 2005;330:45.

96. Gupta MA, Gupta AK. Psychodermatology: An update. J Am Acad Dermatol. 1996;34:1030-1046.

97. Bloch B. Über die heilung der warzen durch suggestion. Klin Wochnschr. 1927;6:2271-2275, 2320-2325. German.

98. Sulzberger MB, Wolf J. The treatment of warts by suggestion. Med Rec. 1934;140:552-556.

99. Obermayer ME, Greenson RR. Treatment by suggestion of verrucae planae of the face. Psychosom Med. 1949;11:163-164.

100. Ullman M. On the psyche and warts: I. Suggestion and warts: A review and comment. Psychosom Med. 1959;2:473-488.

101. Dudek S. Suggestion and play therapy in the cure of warts in children: A pilot study. J Nerv Ment Dis. 1967;145:37-42.
102. Sheehan DV. Influence of psychosocial factors on wart remission. Am J Clin Hypn. 1978;20:160-164.

103. Clarke GHV. The charming of warts. J Invest Dermatol. 1965;45: 15-21.

104. Stankler RL. A critical assessment of the cure of warts by suggestion. Practitioner. 1967;198:690-694.

105. Felt BT, Hall H, Olness K, et al. Wart regression in children: Comparison of relaxation-imagery to topical treatment and equal time interventions. Am J Clin Hypn. 1998;41:130-138.

106. Levenson H, Persons JB, Pope KS. Behavior therapy and cognitive therapy. In: Goldman HH, editor. Review of General Psychiatry. 5th ed. New York, NY: McGraw-Hill; 2000. p. 472.

107. Shenefelt PD. Biofeedback, cognitive-behavioral methods, and hypnosis in dermatology: Is it all in your mind? Dermatol Ther. 2003;16:114-122.

108. Sarti MG. Biofeedback in dermatology. Clin Dermatol. 1998;16: 711-714.

109. Panconesi E, editor. Lo stress, le emozioni, la pelle. Masson, Milan; 1998. p. 94.

110. Freedman RR. Quantitative measurements of finger blood flow during behavioral treatments for Raynaud's disease. Psychophysiol. 1989;26(4):437-441.

111. Rainville P, Hofbauer RK, Bushnell MC, et al. Hypnosis modulates activity in brain structures involved in the regulation of consciousness. J Cognit Neurosci. 2002;14(6):887-901.

112. Freeman R, Barabasz A, Barabasz M, Warner D. Hypnosis and distraction differ in their effects on cold pressor pain. Am J Clin Hypn 2000;43:137-148.

113. Barrios AA. Understanding Hypnosis: Theory, Scope and Potential. Hauppauge NY: Nova Science Publishers; 2009:87-90.
Psychology Research and Behavior Management

\section{Publish your work in this journal}

Psychology Research and Behavior Management is an international, peerreviewed, open access journal focusing on the science of psychology and its application in behavior management to develop improved outcomes in the clinical, educational, sports and business arenas. Specific topics covered include: Neuroscience, memory \& decision making; Behavior

\section{Dovepress}

modification \& management; Clinical applications; Business \& sports performance management; Social and developmental studies; Animal studies. The manuscript management system is completely online and includes a quick and fair peer-review system. Visit http://www.dovepress. com/testimonials.php to read real quotes from published authors. 